\title{
Tribological Capabilities of Graphene and Titanium Dioxide Nano Additives in Solid and Liquid Base Lubricants
}

\author{
Jankhan Patel ${ }^{(D)}$ and Amirkianoosh Kiani * \\ Silicon Hall: Micro/Nano Manufacturing Facility, Faculty of Engineering and Applied Science, Ontario Tech. \\ University (UOIT), Oshawa, ON L1G 0C5, Canada; jankhankumarnayankumar.patel@uoit.net \\ * Correspondence: amirkianoosh.kiani@uoit.ca
}

Received: 5 March 2019; Accepted: 15 April 2019; Published: 19 April 2019

\begin{abstract}
In this study, the tribological behavior of both liquid (oil) and semi-liquid (grease) lubricants enhanced by multilayer graphene nano platelets and titanium dioxide nano powder was evaluated using ball-on-disk and shaft-on-plate tribo-meters. Oil samples for both 2D graphene nano platelets (GNP) and titanium nanopowders (TiNP) were prepared at three concentrations of $0.01 \% w / w, 0.05$ $\% w / w$ and $0.1 \% w / w$. In addition, $0.05 \% w / w$ mixtures of GNP and TiNP were prepared with three different ratios to analyze collective effects of both nano additives on friction and wear properties. For semi-liquid lubricants, $0.5 \% w / w$ concentrations were prepared for both nano additives for shaft-on-plate tests. Viscosity and oxidation stability tests were conducted on the liquid-base lubricants. Nano powders of both additive and substrate were analyzed using transmission electron microscopy (TEM) and scanning electron microscopy (SEM). In addition, Raman spectroscopy was conducted to characterize the graphene and titanium dioxide. The study shows that adding graphene and titanium dioxide individually sacrifices either the wear or friction of lubricants. However, use of both additives together can enhance friction resistance and wear preventive properties of a liquid lubricant significantly. For a semi-liquid lubricant, the use of both additives together and individually reduces friction compared to base grease.
\end{abstract}

Keywords: titanium dioxide; graphene; grease; base oil; friction; wear

\section{Introduction}

Increasing demand for resources gives us an opportunity to concentrate on sustainable development, and this is not possible without considering all the aspects associated with a system. For automobile and mechanical industries where mating surfaces are used to transfer maximum energy, it is important to reduce both wear and friction, which results in less energy consumption and longer functional life for moving mechanical components in machinery [1]. This can be achieved by making surfaces frictionless or by developing better lubricants that do not just control friction and wear but reduce clotting, oxidation, foaming, and corrosion problems in hydraulic systems [2].

Advancement in nano technology allows researchers to implement different manufacturing processes and evaluate applications of nano materials in a variety of fields. In the past researchers have tried nano additives such as metal [3], metal oxide and sulfide [4,5] organic-inorganic material [6], carbon based materials [7-9], and ionic materials [10] in different lubricants. These additives have shown positive effects on lubrication characteristics due to high surface area, higher diffusion rate, and small particle size. A higher diffusion rate allows lubricants to reduce micro friction, which leads to reduced wear and heat concentration in machining processes [11]. 
Titanium and its oxides from macro to nano scale are widely used by different industries because of their high strength, corrosion resistant nature, bio compatibility, and cost effectiveness [12,13]. For example, titanium powder is used by the marine, aeronautical, chemical, paint, and machinery industries to prevent rust and improve strength without adding more weight to the structure $[12,14]$. Sunscreen lotion contains a high amount of titanium dioxide to protect the skin from UVB and UVA2 rays $[14,15]$. However, titanium has a bad reputation in terms of sliding tribology, due to unstable friction and wear, and higher chances of seizing [12,13]. As per stability tests and microscopy findings, $36 \%$ of nano particles should be smaller than $100 \mathrm{~nm}$ for high dispersibility in the water [15]. In addition, studies show that TiNP produces thick and rutile film on the substrate, which can be used for rustproofing applications in tribology [16].

Graphene allotropes are joined in hexagonal shapes, which are basic structures to form carbon based materials. Carbon based materials are synthesized in versatile structures with different physical and chemical properties; thus, they have the potential to be used for different applications such as energy storage, sensors, cancer phototherapy, and electromechanical devices [17-20]. Graphene can be produced by different methods such as chemical reduction and thermal treatment by Hummer's method [21]. However, in all these methods, there is a possibility of damaging the lattice of the carbon. Also, using toxic oxidizers can result in negative effects on the environment and increase fabrication costs. Finally, greater lattice defects from graphene can have adverse effects on tribology improvement [22]. Studies have proven that graphene multilayer nano additives can be used in engine oil, bentone grease, and hydraulic applications to improve tribological and thermal properties [23-25]. However, graphene produced using different methods has shown diverse effects as a tribo improver.

In this paper, the tribological effects of graphene nano platelets (GNP) and titanium nanopowders (TiNP) individually and together on the friction and wearability of both liquid and semi-liquid lubricants were studied. In the first phase, the liquid-base lubricants were tested at $0.01 \% w / w, 0.05 \%$ $w / w$, and $0.1 \% w / w$ concentrations for each additive. It was found that GNP plays an important role in controlling the coefficient of friction (COF); however, adding TiNP results in lower wear under test conditions. Graphene and titanium dioxide were then added together in different ratios at a total concentration of $0.05 \% w / w$ to understand the effects of the two combined additives on liquid base tribology. For semi-liquid lubricant samples, nano additives were used at a high concentration of $0.5 \% w / w$ for each individual nano powder. Both additives were mixed together in the same way for the liquid lubrication samples. Along with tribological characterization, physical properties such as viscosity and oxidation stability were tested for liquid lubricants. Our results from tribology tests including pin-on-disk and plate-on-shaft tests show that combining both GNP and TiNP can be useful for controlling both COF and wear. The results are based on test conditions, however, the concept can be used for synthetic forms of lubricants with enhanced wearability and controlled friction according to the application requirements.

\section{Experimental Methods}

\subsection{Materials and Sample Preparations}

\subsubsection{Synthesis of Graphene and Titanium Dioxide}

Two-dimensional (2D) graphene nano-platelets (GNP) were synthesized from aqueous graphite in the presence of lysozyme [26]. To prepare graphene, graphite powder and protein were mixed and sonicated for $6 \mathrm{~h}$ to get a higher dispersibility. End product powder was collected and centrifuged to remove un-exfoliated graphite and collect smaller sheets of graphene. Lysozyme graphene is $\mathrm{pH}$ sensitive, and this can be useful to prevent conglomeration of graphene in the base oil. Titanium dioxide nano powder was obtained from Sigma-Aldrich. Transmission electron microscopy (TEM) revealed the size of the nano particles to be around $21 \mathrm{~nm}$. The white powder of titanium dioxide had a surface area of $35-65 \mathrm{~m}^{2} / \mathrm{g}$. Trace metal analysis of the nano powder discloses $99.5 \%$ purity. 


\subsubsection{Nano Lubrication Preparation}

Pure oil provided by Petro Canada Inc. was used to prepare the liquid base lubrication samples. Crystal clear oil has $99.9 \%$ purity (Product code: N200MHT). The pour point and flash point (method: Cleveland open cup) of the base oil was found to be $-18{ }^{\circ} \mathrm{C}$ and $240{ }^{\circ} \mathrm{C}$. The density of base oil was $0.865 \mathrm{~kg} / \mathrm{L}$. The GNP and TiNP were mixed at three different concentrations of $0.01 \%, 0.05 \%$, and $0.1 \%$ into the base oil using a mechanical mixer at $1500 \mathrm{rpm}$ for $30 \mathrm{~min}$ for homogeneous dispersion. TiNP and GNP were added in three ratios at $0.05 \% w / w$ concentration as shown in Table 1 . The mechanical mixer was cleaned after each use. Samples were ultrasonicated for $30 \mathrm{~min}$ at room temperature to break the conglomeration of nano platelets.

Table 1. Sample characteristics of liquid base lubricants (liquid nano lubricants).

\begin{tabular}{ccc}
\hline Characterization & Weight Concentration & Type of Additive in a Base Oil (99.9\% Pure) \\
\hline S-1 & $0.01 \% w / w$ & Graphene \\
S-2 & $0.05 \% w / w$ & Graphene \\
S-3 & $0.1 \% w / w$ & Graphene \\
S- 4 & $0.01 \% w / w$ & Titanium dioxide \\
S- 5 & $0.05 \% w / w$ & Titanium dioxide \\
S-6 & $0.1 \% w / w$ & Titanium dioxide \\
S-7 & $0.05 \% w / w$ & Graphene $(50 \%)+$ Titanium dioxide $(50 \%)$ \\
S- 8 & $0.05 \% w / w$ & Graphene $(25 \%)+$ Titanium dioxide $(75 \%)$ \\
S-9 & $0.05 \% w / w$ & Graphene $(75 \%)+$ Titanium dioxide $(25 \%)$ \\
\hline
\end{tabular}

The semi-liquid lubricant (grease) used in this study was commercially available white grease (National Lubricating Grease Institute (NLGI) grade-2), which can be used for applications such as automotive industries and marine and farm equipment. The temperature capability of this grease is between $-15{ }^{\circ} \mathrm{C}$ and $120^{\circ} \mathrm{C}$. Grease samples were rigorously prepared at $0.5 \%$ concentration as per literature review using a magnetic mixer and were also ultrasonicated for $30 \mathrm{~min}$ at $120^{\circ} \mathrm{C}$ (Table 2).

Table 2. Sample characterization of semi-liquid lubricants (grease nano lubricants).

\begin{tabular}{ccc}
\hline Characterization & Weight Concentration & Type of Additive in Grease (Commercial Grease) \\
\hline G-1 & $0.5 \% w / w$ & Graphene \\
G-2 & $0.5 \% w / w$ & Titanium dioxide \\
G-3 & $0.5 \% w / w$ & Graphene $(50 \%)+$ Titanium dioxide $(50 \%)$ \\
G-4 & $0.5 \% w / w$ & Graphene $(25 \%)+$ Titanium dioxide $(75 \%)$ \\
G-5 & $0.5 \% w / w$ & Graphene $(75 \%)+$ Titanium dioxide $(25 \%)$ \\
\hline
\end{tabular}

\subsection{Characterization}

\subsubsection{Raman Test}

Nondestructive Raman spectroscopy tests were conducted using a Renishaw Raman imaging microscope System 2000 (Raman lab at UOIT, ON, Canada). To obtain the most intense excitation peaks, a $514 \mathrm{~nm}$ wavelength laser was used. Each test was conducted at $0.5 \mathrm{~W}$ power for 10 accumulations. Statistical analysis was performed to characterize the multilayer graphene and annealed titanium dioxide. 


\subsubsection{Viscosity}

Kinematic viscosity tests were conducted as per ASTM D445 at Kinectrics, Toronto, Ontario, Canada to obtain data that can be compared to commercial oil. From the kinematic viscosity obtained at $40{ }^{\circ} \mathrm{C}$ and $100^{\circ} \mathrm{C}$, the kinematic viscosity index was calculated. For the viscosity test, the oil was kept in a calibrated glass container overnight to get it settled and afterward the change in viscosity was evaluated in a $40^{\circ} \mathrm{C}$ and $100{ }^{\circ} \mathrm{C}$ warm bath.

\subsubsection{Rotating Pressure Vessel Oxidation Test (RPVOT)}

Anti-oxidation tests were conducted as per ASTM standard D2272 at Kinectrics to evaluate the effect of different nano additives on lubricant oxidation stability. Oxidation stability is directly proportional to the service life of the lubricant, and this can have a greater effect on the sustainability and economics of an industry. To perform the test, lubricant, water, and copper catalyst were placed in a pressurized gauge. Oxygen was then injected into the vessel at $620 \mathrm{kPa}$. The temperature was elevated to $150{ }^{\circ} \mathrm{C}$ and the vessel was rotated at $100 \mathrm{rpm}$. The total time was calculated between the pressure drop from $620 \mathrm{kPa}$ to $24.5 \mathrm{kPa}$, which is noted as oxidation time in minutes.

\subsubsection{TEM and SEM}

Transmission electron microscopy (TEM) was conducted at The Hospital for Sick Children (Sick Kids), Toronto, Ontario, Canada to understand the morphology of the material at higher magnifications. The samples were prepared using epoxy material and sliced into $90 \mathrm{~nm}$ slices using a diamond knife. Morphology images were captured at Sick Kids. A detailed examination of worn disk scars was performed using scanning electron microscopy (SEM).

\subsubsection{Ball-on-Disk Test}

Friction and wear tests were conducted using the ball-on-disk tribometer under in situ conditions at Nanovea. To evaluate the effect of nano additives under loading conditions, a $20 \mathrm{~N}$ load was applied to the pin. Each test was conducted for $20 \mathrm{~min}$, during which the speed of the disk was increased from $0.01 \mathrm{rpm}$ to $150 \times \mathrm{rpm}$ logarithmically. Wear track diameter was found to be $20 \mathrm{~mm}$ when the ball diameter was $6 \mathrm{~mm}$. In addition, the test temperature was maintained at $24^{\circ} \mathrm{C}$ and humidity was kept to $40 \%$ for all the tests to overcome the environmental effects on the lubricants. To calculate the wear rate, hole volume analysis was performed in situ conditions. Surface structure was analyzed as per ISO 25178 standard.

\subsubsection{Shaft-on-Plate}

Grease samples were studied for friction behavior with and without the presence of nano additives using the shaft-on-plate tribo tester at UOIT, Ontario, Canada. Two plates were forced from both sides of the rotary shaft to evaluate the friction coefficient at $30 \mathrm{~N}$ load. Friction force was obtained along with the time. Each test was conducted at room temperature for $20 \mathrm{~min}$. 


\subsubsection{Statistical Analysis}

Statistical analysis was conducted using Microsoft Excel software to maintain the authenticity of data. Moreover, $5 \%$ error was considered for TEM particle size diameter calculations. To compare and analyze the significance of various process groups, one-way ANOVA was utilized. For dimensional characterization of nano particles, 20 measurements were conducted using Image J software. All the data and results shown in this study demonstrate statistical significance unless it has been stated otherwise.

\section{Results}

\subsection{TEM Analysis}

Graphene and titanium dioxide powders tend to conglomerate; thus, when imaging the GNP and TiNP, epoxy was used to mold the powder. Nano-sliced pieces of the epoxy were observed under transmission electron microscopy (TEM) at $25.0 \mathrm{kx}$ magnification of $1 \mu \mathrm{m}$ size. Figure $1 \mathrm{~A}$ is a TEM image of GNP, which discloses a 2D structure with multiple layers. In Figure 1B, the titanium dioxide shows round particles conglomerated in the small chains. Figure 1C indicates the mixed form of graphene and titanium dioxide, demonstrating how titanium particles stick to the graphene surfaces, which motivated us to investigate the tribological properties of both additives together.
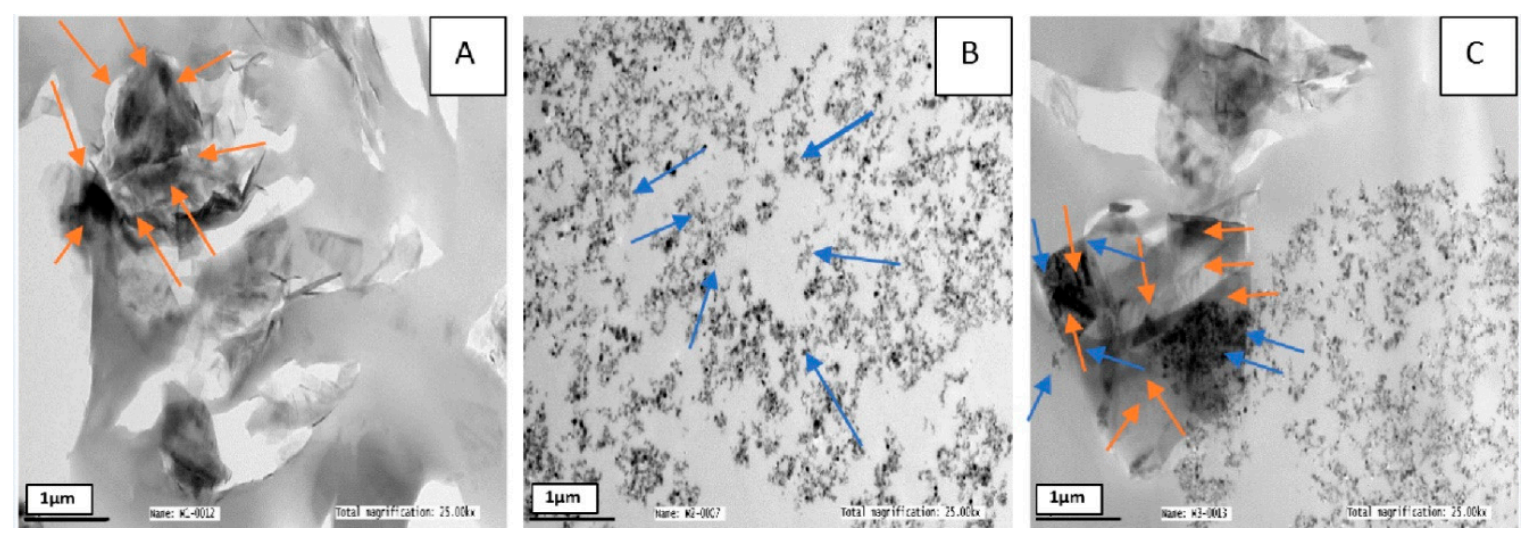

Figure 1. TEM images of (A) graphene, (B) titanium dioxide, and (C) graphene and titanium dioxide mixed together in powder form at $1 \mu \mathrm{m}$ scale and $25.00 \mathrm{kx}$ magnifications.

\subsection{Raman Results}

Raman spectroscopy allows us to determine the characteristics of the nano additives used in this research. It identifies defects in the carbon lattice by generating different intensity peaks using nondestructive methods. As illustrated in Figure 2, Raman spectroscopy illustrates the main peaks at different wavelengths of $\sim 1354 \mathrm{~cm}^{-1}$ (D band), $\sim 1581 \mathrm{~cm}^{-1}$ (G band), and $\sim 2719 \mathrm{~cm}^{-1}$ (2D band). The $\mathrm{sp}^{2} \mathrm{D}$ carbon mode requires defects for activation which is illustrated by the $\mathrm{D}$ band intensity. In addition, the narrow $G$ band demonstrates that optical $E_{2 g}$ phonons are in the Brillouin zone due to stretching in $\mathrm{sp}^{2}$ chains, bond, and rings. The D + D' peak at $\sim 2959 \mathrm{~cm}^{-1}$ shows the exfoliation of graphite. The intensity ratio at the $\mathrm{D}$ and $\mathrm{G}$ bands is important to understand the transformation of $\mathrm{sp}^{3}$ to $\mathrm{sp}^{2}$ conversion of carbons; further, it is directly proportional to the defect rate. This graphene sample, Id/Ig is 0.153 , is very low compared to restored graphene, proving that this graphene has very few defects in the carbon lattice $[27,28]$. Along with that, lower D band intensity, with respect to $G$ band, support less lattice defect in graphene layers [29]. 


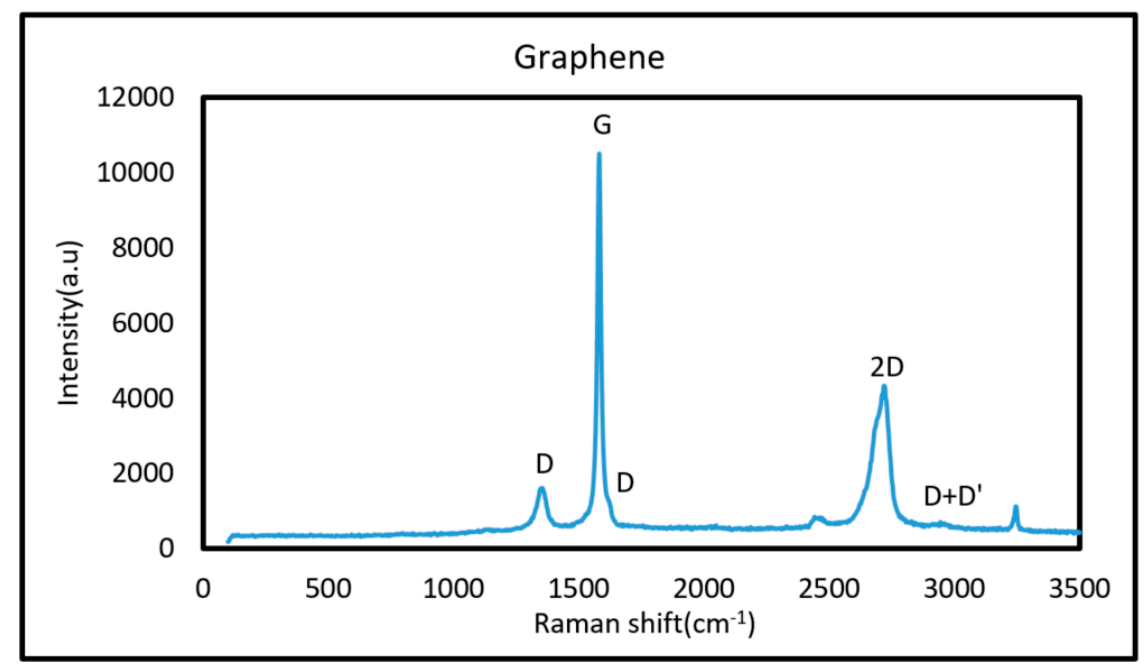

Figure 2. Raman spectroscopy of graphene nano particles.

Titanium dioxide nano powder was investigated by the Raman technique as demonstrated in Figure 3. The powder generates a primary peak at $\sim 144 \mathrm{~cm}^{-1}$ and secondary intensity peaks at $\sim 199 \mathrm{~cm}^{-1}, \sim 397 \mathrm{~cm}^{-1}, \sim 516 \mathrm{~cm}^{-1}, \sim 638 \mathrm{~cm}^{-1}$, which is associated with different modes of energy such as $E_{g}$ (strong), $E_{g}$ (weak), $B_{1 g}, A_{1 g}+B_{1 g}, E_{g}$ (intermediate), respectively [30]. These peaks represent the characteristics of the anatase phase of titanium dioxide nano particles.

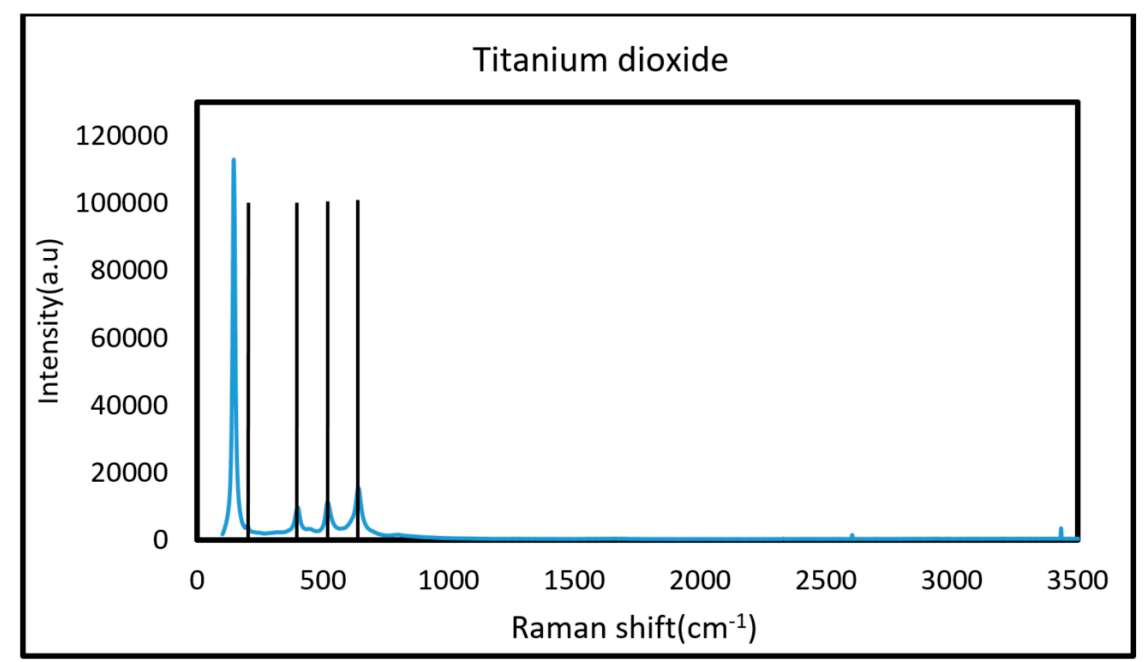

Figure 3. Raman spectroscopy of titanium dioxide nano particles.

\subsection{Kinematic Viscosity}

To compare the effects of different concentrations and types of nano additives in liquid base lubricants, kinematic viscosity tests were performed as per ASTM standards. Kinematic test results disclose the viscosity of nano lubricants at $40^{\circ} \mathrm{C}$ and $100^{\circ} \mathrm{C}$. The resistance of lubricants to changes in temperature (viscosity index) is important to improve hydrodynamic lubrication regimes at large temperature ranges. As per the base oil data sheet provided by Petro Canada, viscosities at $40{ }^{\circ} \mathrm{C}$ and $100{ }^{\circ} \mathrm{C}$ are $41.5 \mathrm{~mm}^{2} / \mathrm{s}$ and $6.3 \mathrm{~mm}^{2} / \mathrm{s}$, respectively. The calculated viscosity index for base oil is 98 . However, results shown in Figure 4 prove that there is no difference in viscosity at both temperatures, nor in the viscosity index except S-3. Results demonstrate that improvement in tribology applications does not lead to sacrifices in physical properties. 

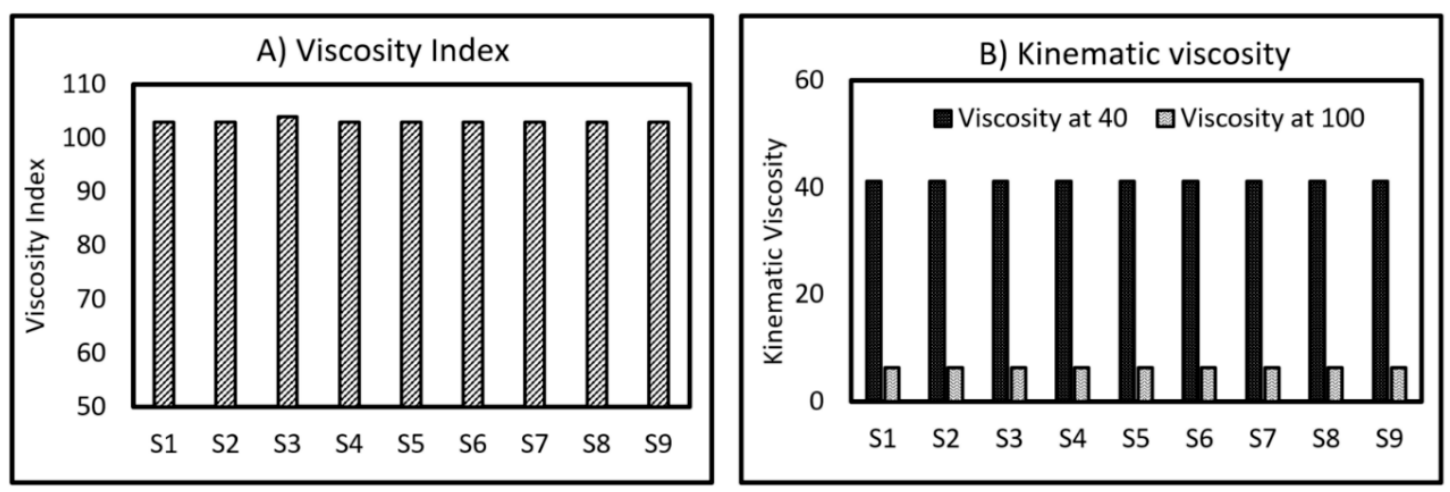

Figure 4. Viscosity index (A) and Kinematic viscosity (B) of liquid lubricants.

\subsection{RPVOT}

Anti-oxidation capabilities of lubricants were evaluated using the rotating pressure vessel oxidation test (RPVOT) as per ASTM standards. For sustainable improvement, it is important to consider the lubricant's service life, as lubricants that are not antioxidant can start causing cavitation in the system, which requires changing parts and lubricant. This damages the economic performance of the industry and generates environmental waste. As shown in Figure 5, there is no significant difference in oxidation time using these additives compared to base oil oxidation time. Base oil has shown oxidation time as $27.1 \mathrm{~min}$ under the same conditions. This proves that except for S-1, S-3, and S-6, all other samples increase oxidation stability, which allows the lubricant to have a longer service life. Test results conclude that this additive will not damage the economic performance of industries if it is added to the lubricant.

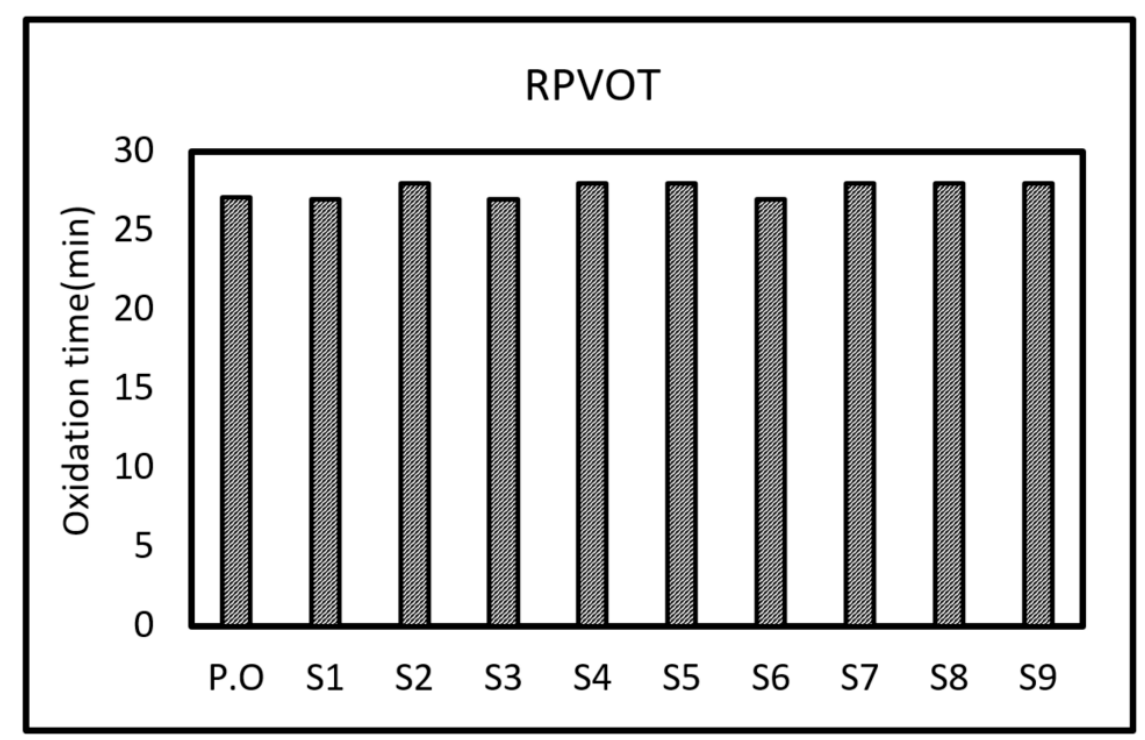

Figure 5. Rotating pressure vessel oxidation test (RPVOT) anti-oxidation test.

\subsection{Friction and Wear of Liquid Base Lubricants}

To obtain comparative data about the tribological effects of GNP and TiNP additives to fluid lubricants, friction and wear tests were conducted using a pin-on-disk tester. For semi-liquid samples (grease), a shaft rotatory shaft-on-plate test was used as described in the experimental setup. For liquid base lubricants, anti-scuffing and friction coefficients were calculated using in situ conditions. As demonstrated in Figure 6, a higher concentration of graphene nano additives reduces the friction coefficient; however, wear preventive properties are sacrificed. Comparing titanium dioxide with graphene illustrates that it can significantly lower the wear; however, a higher concentration of TiNP 
additive does not significantly affect wear preventive properties. As explained, a $0.05 \%$ concentration reveals less friction for the graphene sample. For titanium, it has lowered wear, which led us to prepare the $0.05 \%$ concentration using three different weight ratios of the additive. As illustrated, S- 8 shows a lower friction coefficient and S-9 proves the lowest wear.

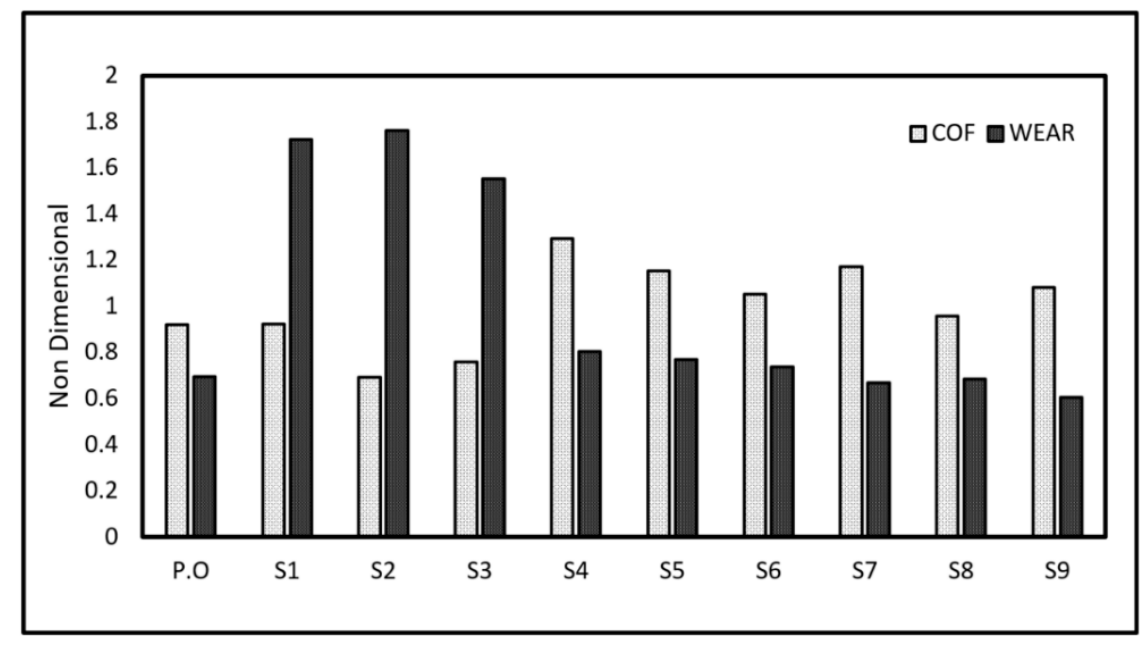

Figure 6. Friction coefficient and wear data (method for normalization: Z-score).

The results of the liquid lubricant samples enhanced by GNP and TiNP were compared separately at different concentrations. In addition, the S-2 and S-4 nano additive concentrations were found comparatively effective for hybrid nano additives of GNP and TiNP; thus, three ratios and nano additives at this concentration $(0.05 \%)$ were prepared and tested. The results displayed in Figure 6 manifest that GNP has a higher wear rate compared to the coefficient of friction. However, the TiNP samples reveal a lower wear rate and higher friction coefficient. This motivated our research to evaluate the tribological effects of these additives together. S-8 illustrates moderate wear as well as friction. Along with that, S-9 shows the lowest wear but is compromised by friction. In addition, S-7 demonstrates better control on wear but it gains higher friction.

\subsection{SEM Microscopy}

Analysis of the worn disk helps us to understand the difference in the wear characteristics of different nano additives to lubricants. Disk wear track was evaluated at the $40 \mu \mathrm{m}$ resolution and 1500 kx magnification in a low vacuum chamber using SEM as revealed in Figure 7. The worn surface of S-1 reveals that abrasive and adhesive wear can be seen from surface damage. This can be the result of debris penetration at the contact patch, which leads to the generation of rough surfaces. S-2 and S-3 show a higher number of pits on the surface, which can be caused by the micro crack on the substrate surface. Along with that, these pits cause an imbalance in the elastic hydrodynamic condition which can also cause corrosion on the surface [31]. Morphology of S-4 and S-6 express smooth wear tracks; however, longer surface removal marks can be seen, which indicates adhesive wear. In addition, for S-5 some plastic deformation can be found on the side of the surface. This kind of adhesive wear can be caused by micro cracks, which enlarge under continuous loading conditions. S-7 shows fatigue wear where micro cracks enlarge gradually, which causes removal of surface material that can also be called mechanical pitting. In S-8 and S-9, smooth wear track marks are visible on the substrate, which displays slight adhesive wear; however, no plastic deformation nor any abrasive wear is seen on these samples. 
Further investigation of the wear track was conducted when the surface texture was examined as per ISO standard 25178. Different data were recorded including arithmetic mean height, which is important for understanding the surface waviness of the scar. As demonstrated in Figure 8, S-1 and S-5 show higher mean height with respect to the other samples, which disclose that larger peaks and valleys were found on the substrate. S-9 reveals the lowest mean height, indicating a smooth wear track.
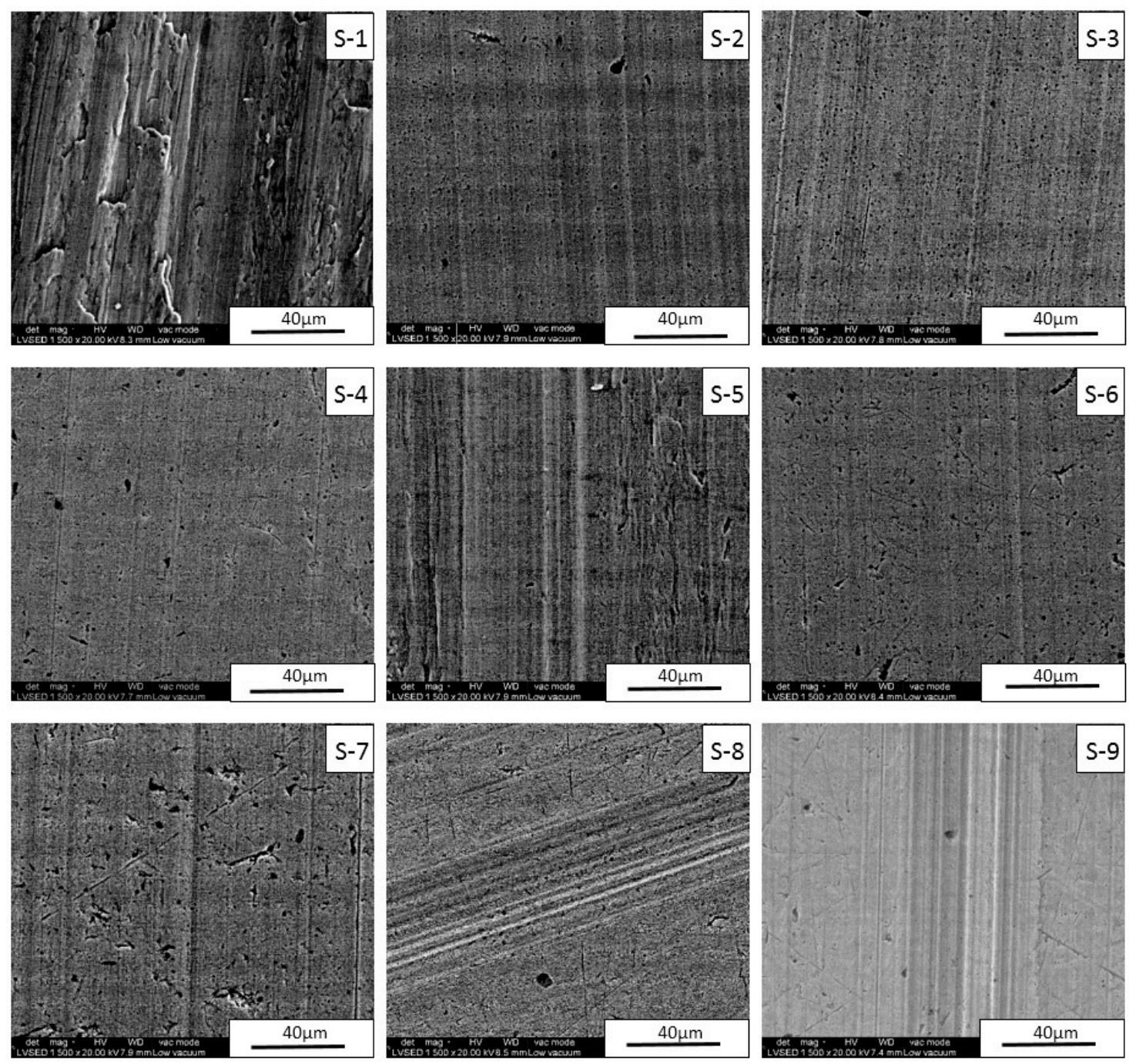

Figure 7. Worn scar evaluation in a low vacuum chamber at $40 \mu \mathrm{m}$ scale using SEM for nine disk samples. 


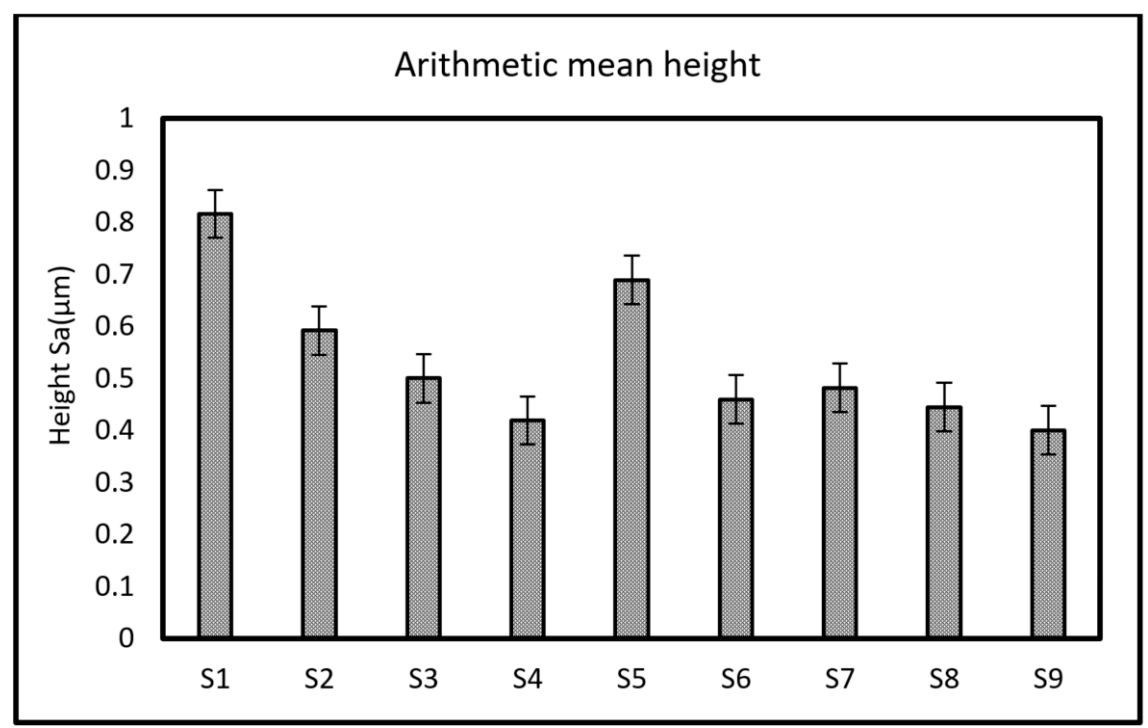

Figure 8. Arithmetic mean height of wear scar on the disk.

\subsection{Frictional Results With Grease}

Nano additive grease was tested using the prototyped rotatory plate-on-shaft friction system at the University of Ontario Institute of Technology. Semi-liquid lubricants (white grease) enhanced by GNP, TiNP, and a combination of both, were tested at $10 \mathrm{~N}, 20 \mathrm{~N}$, and $30 \mathrm{~N}$ load conditions to evaluate the frictional properties of the grease. Higher concentrations of nano additives increase the dispersibility of particles in the grease. Initially, two samples were prepared where $0.5 \% w / w$ nano particles were added. As demonstrated in Figure 9, G1 reduces friction drastically at the $20 \mathrm{~N}$ load, the same as TiNP. However, at $30 \mathrm{~N}$ it was found that the thickness of hydrodynamic films becomes thinner, showing the minimal difference between white grease and nano particle enhanced grease. It was found that G3 (ratio of GNP/TiNP:1) manifests an increment in friction. However, G4 (lower graphene concentration and a higher titanium dioxide concentration) discloses the highest reduction in friction at the $20 \mathrm{~N}$ load. G5 (higher concentration of graphene and a lower concentration of titanium dioxide) shows a slight increment in average friction coefficient at the $20 \mathrm{~N}$ load. Each test was conducted at least 3 times and average data were considered to mitigate testing errors. To recapitulate, all 5 nano grease samples enhance the antifriction properties of the semi-liquid lubricant.

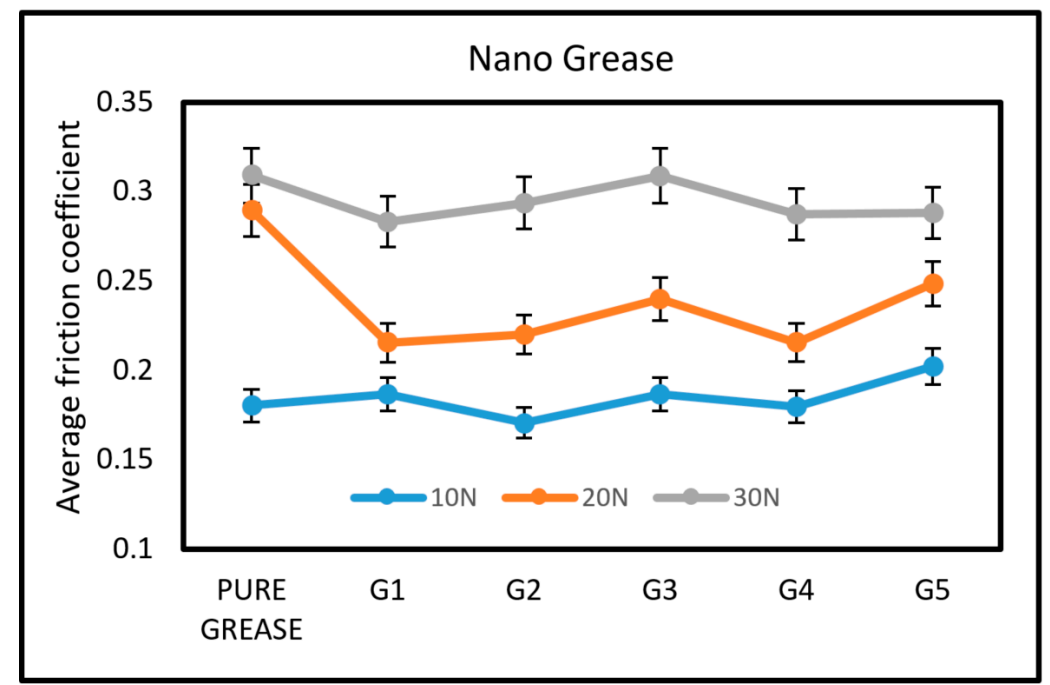

Figure 9. The average friction coefficient of nano additive grease at $10 \mathrm{~N}, 20 \mathrm{~N}$, and $30 \mathrm{~N}$ normal load. 


\section{Conclusions}

This study was conducted to evaluate the tribological and physical properties of graphene and titanium dioxide. Results show positive effects on base lubricants. Both nano additives showed no negative effect on oxidation life and viscosity; however, both additives reveal modifications in friction and wear properties. GNPs demonstrate a great control over friction at $0.05 \% w / w$ concentration; however, GNP sacrifices its wear preventive properties compared to titanium dioxide. On the other hand, titanium dioxide nano particles manifest the highest wear resistivity at $0.1 \% w / w$ concentration; but again, friction is higher compared to the graphene nano particles. However, for mixed nano additives of GNP and TiNP, it was found that both wear and coefficient of friction (COF) can be controlled as per application requirements, as S-9, which has a higher concentration of graphene and lower concentration of titanium dioxide, revealed the least wear. A higher concentration of titanium dioxide and a lower concentration of graphene showed more control of friction than wear.

For semi-liquid lubricants (white grease), both GNP and TiNP additives manifest lower friction coefficients (COF). In addition, the amalgamation of both nano additives lower friction compared to pure grease at the $20 \mathrm{~N}$ load. There is not much change in the friction coefficient at the $30 \mathrm{~N}$ high load because of the extremely thin film of grease on the shaft, which does not allow additives to enter the point of contact. However, at the $20 \mathrm{~N}$ load, a higher concentration of GNP and a lower concentration of TiNP indicates the highest reduction in friction compared to the pure grease.

Author Contributions: Conceptualization, A.K.; methodology, J.P. and A.K.; validation, A.K.; formal analysis, J.P.; investigation, J.P.; resources, A.K.; data curation, A.K.; writing-original draft preparation, J.P. and A.K.; writing-review and editing, A.K. and J.P.; visualization, J.P.; supervision, A.K.; project administration, A.K.; funding acquisition, A.K.

Funding: This research was partially funded by the National Sciences and Engineering Research Council (NSERC).

Acknowledgments: The authors would like to acknowledge research support for rotatory plate-on-shaft friction system provided by Ahmad Barari at Ontario Tech. University.

Conflicts of Interest: The authors declare no conflicts of interest.

\section{References}

1. Berman, D.; Erdemir, A.; Sumant, A.V. Graphene: A new emerging lubricant. Mater. Today 2014, 17, 31-42. [CrossRef]

2. Stachowiak, G.; Batchelor, A. Lubricants and their composition. In Engineering Tribology; Elsevier: Oxford, UK, 2006; pp. 51-101.

3. Choi, C.; Jung, M.; Choi, Y.; Lee, J.; Oh, J. Tribological properties of lubricating oil-based nano fluids with metal/carbon nanoparticles. J. Nanosci. Nanotechnol. 2011,11, 368-371. [CrossRef]

4. Alves, S.; Barros, B.; Trajano, M.; Ribeiro, K.; Moura, E. Tribological behavior of vegetable oil-based lubricants with nanoparticles of oxides in boundary lubrication conditions. Tribol. Int. 2013, 65, 28-36. [CrossRef]

5. Kang, X.; Wang, B.; Zhu, L.; Zhu, H. Synthesis and tribological property study of oleic acid-modified copper sulfide nanoparticles. Wear 2008, 265, 150-154. [CrossRef]

6. Kim, D.; Archer, L.A. Nanoscale organic- inorganic hybrid lubricants. Langmuir 2011, 27, 3083-3094. [CrossRef] [PubMed]

7. Patel, J.; Kiani, A. Effects of reduced graphene oxide (rGO) at different concentrations on tribological properties of liquid base lubricants. Lubricants 2019, 7, 11. [CrossRef]

8. Kamel, B.M.; Mohamed, A.; El Sherbiny, M.; Abed, K. Tribological behavior of calcium grease containing carbon nanotubes additives. Ind. Lubr. Tribol. 2016, 68, 723-728. [CrossRef]

9. Liang, S.; Shen, Z.; Yi, M.; Liu, L.; Zhang, X.; Ma, S. In-situ exfoliated graphene for high-performance water-based lubricants. Carbon 2016, 96, 1181-1190. [CrossRef]

10. Patel, A.; Guo, H.; Iglesias, P. Study of the lubricating ability of Protic ionic liquid on an aluminum-steel contact. Lubricants 2018, 6, 66. [CrossRef]

11. Bhushan, B. Nanotribology and nanomechanics. Wear 2005, 259, 1507-1531. [CrossRef] 
12. Kang, J.; Wang, M.; Yue, W.; Fu, Z.; Zhu, L.; She, D.; Wang, C. Tribological behavior of titanium alloy treated by nitriding and surface texturing composite technology. Materials 2019, 12, 301. [CrossRef] [PubMed]

13. Dong, H. Tribological properties of titanium-based alloys. In Surface Engineering of Light Alloys; Elsevier: Amsterdam, The Netherlands, 2010; pp. 58-80.

14. Rai, R.; Shanmuga, S.C.; Srinivas, C. Update on photo protection. Indian J. Dermatol. 2012, 57, 335. [CrossRef] [PubMed]

15. Weir, A.; Westerhoff, P.; Fabricius, L.; Hristovski, K.; von Goetz, N. Titanium dioxide nanoparticles in food and personal care products. Environ. Sci. Technol. 2012, 46, 2242-2250. [CrossRef] [PubMed]

16. Mohammed, M.T.; Khan, Z.A.; Siddiquee, A.N. Surface modifications of titanium materials for developing corrosion behavior in human body environment: A review. Procedia Mater. Sci. 2014, 6, 1610-1618. [CrossRef]

17. Hong, J.-Y.; Jang, J. Micro patterning of graphene sheets: Recent advances in techniques and applications. J. Mater. Chem. 2012, 22, 8179-8191. [CrossRef]

18. Zhang, H.; Gruener, G.; Zhao, Y. Recent advancements of graphene in biomedicine. J. Mater. Chem. B 2013, 1, 2542-2567. [CrossRef]

19. Li, P.F.; Zhou, H.; Cheng, X. Investigation of a hydrothermal reduced graphene oxide nano coating on $\mathrm{Ti}$ substrate and its nano-tribological behavior. Surf. Coat. Technol. 2014, 254, 298-304. [CrossRef]

20. Berman, D.; Erdemir, A.; Sumant, A.V. Reduced wear and friction enabled by graphene layers on sliding steel surfaces in dry nitrogen. Carbon 2013, 59, 167-175. [CrossRef]

21. Park, S.; Ruoff, R.S. Chemical methods for the production of graphene. Nat. Nanotechnol. 2009, 4, 217. [CrossRef]

22. Penkov, O.; Kim, H.-J.; Kim, H.-J.; Kim, D.-E. Tribology of graphene: A review. Int. J. Precis. Eng. Manuf. 2014, 15, 577-585. [CrossRef]

23. Fan, X.; Xia, Y.; Wang, L.; Li, W. Multilayer graphene as a lubricating additive in bentone grease. Tribol. Lett. 2014, 55, 455-464. [CrossRef]

24. Eswaraiah, V.; Sankaranarayanan, V.; Ramaprabhu, S. Graphene-based engine oil nano fluids for tribological applications. ACS Appl. Mater. Interfaces 2011, 3, 4221-4227. [CrossRef]

25. Zin, V.; Barison, S.; Agresti, F.; Colla, L.; Pagura, C.; Fabrizio, M. Improved tribological and thermal properties of lubricants by graphene based nano-additives. RSC Adv. 2016, 6, 59477-59486. [CrossRef]

26. Joseph, D.; Tyagi, N.; Ghimire, A.; Geckeler, K.E. A direct route towards preparing pH-sensitive graphene nanosheets with anti-cancer activity. RSC Adv. 2014, 4, 4085-4093. [CrossRef]

27. Kudin, K.N.; Ozbas, B.; Schniepp, H.C.; Prud'Homme, R.K.; Aksay, I.A.; Car, R. Raman spectra of graphite oxide and functionalized graphene sheets. Nano Lett. 2008, 8, 36-41. [CrossRef] [PubMed]

28. Wang, H.L.; Robinson, J.T.; Li, X.L.; Dai, H.J. Solve thermal reduction of chemically exfoliated graphene sheets. J. Am. Chem. Soc. 2009, 131, 9910-9911. [CrossRef] [PubMed]

29. Croce, A.; Arrais, A.; Rinaudo, C. Raman micro-spectroscopy identifies carbonaceous particles lying on the surface of crocidolite, amosite, and chrysotile fibers. Minerals 2018, 8, 249. [CrossRef]

30. Gupta, S.K.; Desai, R.; Jha, P.K.; Sahoo, S.; Kirin, D. Titanium dioxide synthesized using titanium chloride: Size effect study using raman spectroscopy and photoluminescence. J. Raman Spectrosc. 2010, 41, 350-355. [CrossRef]

31. Souza, J.C.; Henriques, M.; Teughels, W.; Ponthiaux, P.; Celis, J.-P.; Rocha, L.A. Wear and corrosion interactions on titanium in oral environment: Literature review. J. Bio- Tribo-Corros. 2015, 1, 13. [CrossRef]

(C) 2019 by the authors. Licensee MDPI, Basel, Switzerland. This article is an open access article distributed under the terms and conditions of the Creative Commons Attribution (CC BY) license (http://creativecommons.org/licenses/by/4.0/). 